\title{
POST-PARTUM PSYCHOSIS; CULTURAL ISSUE AND THERAPEUTIC BARRIERS AND REGIONAL THERAPISTS
}

\author{
Reza Bidaki ${ }^{1}$, Pardis Safapour ${ }^{2}$, Emad Seyedchi ${ }^{3}$, Mohammad Hossein Sorbi ${ }^{4 *}$ \\ ${ }^{1}$ Research Center of Addiction and Behavioral Sciences, Shahid Sadoughi University of Medical Sciences, Yazd, Iran \\ ${ }^{1}$ Research Center of Diabetes, Shahid Sadoughi University of Medical Sciences, Yazd, Iran \\ ${ }^{2,3}$ Medical Student, Student Research Committee, Shahid Sadoughi University of Medical Sciences, Yazd, Iran \\ *4 Master of Science of Clinical Psychology, Faculty of Medicine, Kermanshah University of Medical Science, \\ Kermanshah, Iran.
}

*Corresponding author: -

E-Mail: Sorbih@yahoo.com Tel: (+98)9131560290

\begin{abstract}
: -
Catatonia is a state that a person who is awake does not respond to any external stimuli. The term cultural bound syndrome refers to anyone who has recurrences, locality-specific patterns of aberrant behavior and experiences that appear to fall outside conventional Western psychiatric diagnostic categories. In this case we are presenting a young woman who had given birth, and it was followed by an acute and extreme stressor. She suffered from severe anxiety and the symptoms of catatonia.
\end{abstract}

Keywords: - Post-Partum, Psychosis, Cultural, issue, Barriers, and, Regional, Therapists 


\section{INTRODUCTION}

Catatonia is a state that a person who is awake does not respond to any external stimuli. We have 3 types of catatonia by its etiology (1) includes associated with the mental disorder (2), associated with the medical condition of the patient (3), and unspecified catatonia (4). This disease manifest some signs and symptoms as allogia, Negativism, Echolalia, Echopraxia, Waxy flexibility and Withdrawal (5). There are some cultural factors on the postpartum schizophrenia. For example catatonia may be less in developing countries than developed ones because physicians fail to diagnose the condition in their patients.

On the other hand, the term cultural bound syndrome refers to anyone who has recurrences, locality-specific patterns of aberrant behavior and experiences that appear to fall outside conventional western psychiatric diagnostic categories. Cultural concepts, values, beliefs, influence health-seeking pathways and traditional healers play an important role in the management of disease in many cultures where 'Western' medicine is unavailable, viewed with skepticism or is used in parallel with traditional treatment methods (6). Another cultural factor in this illness is lack of information that has important negative effects. This problem can be resolved by education or information alone and it may be the case that on cultures which using ideographs, the illness will need to be renamed $(7,8)$.

In this case we are presenting a young woman who had given birth, and it was followed by an acute and extreme stressor. She suffered from severe anxiety and the symptoms of catatonia.

\section{Case presentation}

We report a young married 25 year-old female from Zabol and lived in Bam for a while and now she lives in Rafsanjan (Three cities and different cultures). She experienced her first pregnancy without significant history of psychological problems . She had given birth to her second child that was followed by an acute and extreme stressor. Immediately, follow second delivery, She suffered from severe anxiety, agitation, fear of spirits, insomnia, loss of interest, impaired interpersonal relationship, refuse of eating, social withdrawal, and after 48 hours the symptoms of catatonia include stupor, alogia, fasting, negativism were appeared.

Her family referred her to a tropical therapist. He got a series rituals as treatment for her but it didn't work. They refereed to other tropical therapist again and again. Finally they became disappointment and she was deteriorated. Therefore, they decided to get aid of a psychiatrist. She came with these signs and symptoms such as astonishment, persistent crying, allogia or mutism, extreme slowness in psychomotor activities, visual hallucination, flat affect, rigidity and starving for a while. She had sleeping disorder and no desire for caring her baby. We did some examination on her to rule out the medical problems and her lab data and brain computed tomography (CT) showed no lesions.

We started serum therapy for malnutrition and dehydration. Drugs were Risperidone $2 \mathrm{mg} / \mathrm{Hs}$, Lithium carbonate 300 mg /TDS, Clonazepam $1 \mathrm{mg} / \mathrm{Hs}$, Haloperidol $5 \mathrm{mg} / \mathrm{BID}$, Biperidene $2 \mathrm{mg} / \mathrm{BID}$.

Because of catatonia symptoms we started ECT as soon as possible. After 3th sessions, she fell well and the catatonic symptoms subsided. The next step was family psycho education. We stated training of her family about psychiatric treatments and psychiatric disorders. Her baby was fed via supplementary foods and milk powder.

Finally, she had been discharged without psychotic symptoms and depressive state. We decide introduce and highlight the role of beliefs and ideas of people about psychiatric treatments and approach.

\section{Discussion}

The purpose of this case report is to insist more on the cultural and socioeconomic factors and the role of the patient's family in their prognosis.

Nowadays there are good evidences for socioeconomic and cultural impacts on the course prognosis and even the origin of the schizophrenia (9). As an example, taking medication is on patient's autonomy and his choice by his consent and information about the consequences of his act and as we know lack of information has major negative effects and this problem cannot be resolved with education and information. Resolving this problem needs society's contribution (10). We have had cultural factors in Iran such as Spell, Black magic, Enchantment, Prayer readings and Special ceremonies. These actions have been seen all around the world differently. Native American healing practices include traditional medicine practitioners such as Shaman, herbalists and medicine women and men. These traditional practitioners using traditional medicines such as therapeutic sings, dancing, chants, prayers, purification ceremonies, sand painting, teas, herbs, special foods and etc. Two-thirds of their population using this traditional healing and sometimes in combination with mental health care providers (7).

The IPSS (International Pilot Study on Schizophrenia) and DOSMD (Determinants of Outcomes of Severe Mental Disorder) declared that the course of schizophrenia is more acceptable in developing societies than developed ones (11). The perception of mental disorders related to the cultural dynamics can affect diagnosis and treatment of schizophrenia (12).

\section{Conclusion}

The cultural issues are the most important barriers for mentally ill patients. It may be considerable about pregnant women with serious psychiatric disorder like post partum psychosis and catatonic features.

Authors' contribution: Pardis Safapour and Emad Seyedchi prepared primary draft; Pouria Yazdian-Anari revised it. Reza Bidaki collected data, wrote primary draft, revised and submitted it. 


\section{References}

[1]. Sienaert P, Dhossche DM, Vancampfort D, De Hert M, Gazdag G. A clinical review of the treatment of catatonia. Frontiers in psychiatry. 2014;5:181.

[2]. Poser HM, Trutia AE. Treatment of a Prader-Willi Patient with Recurrent Catatonia. Case reports in psychiatry. 2015;2015:697428.

[3]. Wijemanne S, Jankovic J. Movement disorders in catatonia. Journal of neurology, neurosurgery, and psychiatry. 2014.

[4]. Clinebell K, Azzam PN, Gopalan P, Haskett R. Guidelines for preventing common medical complications of catatonia: case report and literature review. The Journal of clinical psychiatry. 2014;75(6):644-51.

[5]. Dhossche DM. Vagal intimations for catatonia and electroconvulsive therapy. The journal of ECT. 2014;30(2):1115.

[6]. Prochwicz K, Sobczyk A. [Dancing manias. Between culture and medicine]. Psychiatria polska. 2011;45(2):277-87.

[7]. Bodegard G. Depression-withdrawal reaction in refugee children. An epidemic of a cultural-bound syndrome or an endemic of re-traumatized refugees? Acta paediatrica (Oslo, Norway : 1992). 2010;99(7):959.

[8]. Chen CW. [Nursing care of a patient with cultural bound syndrome]. Hu li za zhi The journal of nursing. 1980;27(2):18-25.

[9]. Martin DJ, Park J, Langan J, Connolly M, Smith DJ, Taylor M. Socioeconomic status and prescribing for schizophrenia: analysis of 3200 cases from the Glasgow Psychosis Clinical Information System (PsyCIS). Psychiatric bulletin (2014). 2014;38(2):54-7.

[10]. Agerbo E, Sullivan PF, Vilhjalmsson BJ, Pedersen CB, Mors O, Borglum AD, et al. Polygenic Risk Score, Parental Socioeconomic Status, Family History of Psychiatric Disorders, and the Risk for Schizophrenia: A Danish Population-Based Study and Meta- analysis. JAMA psychiatry. 2015;72(7):635-41.

[11]. Vancampfort D, De Hert M, De Herdt A, Soundy A, Stubbs B, Bernard P, et al. Associations between perceived neighbourhood environmental attributes and self-reported sitting time in patients with schizophrenia: a pilot study. Psychiatry research. 2014;215(1):33- 8.

[12]. D'Souza DC, Radhakrishnan R, Perry E, Bhakta S, Singh NM, Yadav R, et al. Feasibility, safety, and efficacy of the combination of D-serine and computerized cognitive retraining in schizophrenia: an international collaborative pilot study. Neuropsychopharmacology: official publication of the American College of Neuropsychopharmacology. 2013;38(3):492-503. 